\title{
EL COMPLEJO DE TELÉMACO. PADRES E HIJOS TRAS EL OCASO DEL PROGENITOR Massimo Recalcati
}

Catalina Sorhouet Pereira Licenciada en Psicología de la UDELAR Especialista en psicoterapia psicoanalítica del IUPA Profesora adjunta del IUPA Correo electrónico: catalinasorhouet@gmail.com ORCID: 0000-0002-9068-0315 


\section{Massimo Recalcati}

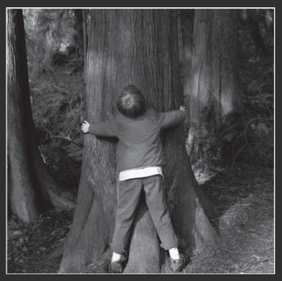

\section{El complejo} de Telémaco

Padres e hijos

tras el ocaso del progenitor
Título: El complejo de Telémaco.

Padres e hijos tras el ocaso del

progenitor

Autor: Massimo Recalcati

Año: 2014

Editorial: Anagrama

Ciudad: Barcelona

Páginas: 168 
Adentrarse en este libro de Recalcati (Milán, 1959) es, de alguna forma, adentrarse en toda su obra.

Es un psicoanalista italiano, autor de múltiples ensayos enfocados principalmente en dos temas: los llamados trastornos alimenticios, donde inaugura el concepto de clínica del vacio, y lo que - considero- podríamos llamar el nuevo malestar en la cultura. El primer ensayo de esta línea es su obra El complejo de Telémaco, donde - a mi entender-queda instalada su tesis sobre el sujeto contemporáneo.

Este nuevo malestar no se aleja completamente de aquel planteado por Freud, pero nos encuentra en una nueva organización social. Según surge de la lectura de la obra de este autor, nos encuentra en una época en la que los viejos modelos están en declive y los nuevos, en formación. En esta línea, y en distintos ensayos, el autor desarrolla nuevas tesis vinculadas a la educación (La hora de clase. Por una erótica de la enseñanza, 2016), la pareja (Ya no es lo de antes. Elogio del perdón en la vida amorosa, 2015) y la familia como formadoras de subjetividad.

Es en otras obras - entre las que se encuentra la que nos interesa en esta reseña- que Recalcati nos invita a problematizar la familia nuclear, la tríada familiar clásica. A través del análisis de esta, de los cambios, las carencias, los nuevos logros y, especialmente, las consecuencias de estos cambios para los más jóvenes, busca teorizar esta nueva realidad desde una perspectiva psicoanalítica. Tales obras son El complejo de Telémaco (2014), dedicado a la figura del padre, Las manos de la madre (2018) y El lugar del hijo (2020).

A través de la clínica, pero también de una aguda observación de los movimientos sociales y culturales, el autor nos invita a situarnos en 
la actualidad y pensar nuestra práctica y el padecimiento de nuestros jóvenes, quienes serán su principal objeto de estudio. Más que un ensayo acabado, El complejo de Telémaco es un generador de pensamiento; ya sea desde la crítica o el acierto, nos moviliza. La cuestión de las nuevas normalidades, los nuevos pacientes difíciles y los desafíos para la psicoterapia psicoanalítica en el mundo actual forma parte de nuestra agenda académica de manera evidente. Es por esto que considero de gran importancia los aportes de este autor.

Tal como lo adelanta su título, este ensayo se basa en la figura de Telémaco, originaria de la mitología griega y personaje de La odisea de Homero. Telémaco es hijo de Ulises y Penélope. Su padre parte de su tierra natal, Ítaca, a la guerra; las peripecias de su viaje demoran su retorno por veinte años. El personaje del hijo que espera el retorno del padre amado para que restaure la ley en la polis, que se ha convertido en un caos desde su partida, será, para Recalcati, un modelo posible de hijo contemporáneo. El hijo a la espera de la ley paterna que se encuentra en franco declive, a la espera de un padre ideal que no conoce, pero añora.

El autor se ocupa de reiterar que no busca el retorno del padre autoritario, sino la aparición de una nueva figura que esté en condiciones de trasmitir la experiencia vital como algo valioso y plausible de ser disfrutado, incluso con sus límites y prohibiciones. Plantea que la indiferenciación entre generaciones puede ser la causa de esta situación, la idealización de la juventud eterna, de lo individual y del goce sin límites que proponen las sociedades actuales. El envejecimiento, muchas veces, supone la desaparición de la vida pública, lo que produce que padres e hijos se presenten como amigos, indiferenciados. Ya no hay un mundo de unos y de otros, todo es el mundo de lo uno.

De esta manera, el hijo-Telémaco se presentará, desde esta perspectiva, como un modelo de sujeto actual. Hiperhedonista, no sabe reconocer límites ni postergar el goce, y consume personas como cosas, lo que 
empobrece la experiencia del encuentro con los otros. Por otra parte, existen distintos elementos individuales y colectivos que nos hacen pensar en este estado de las cosas. Depresión, desprestigio del trabajo como medio para un fin, ineficacia de gobiernos y caída de instituciones dogmáticas clásicas dejan lugar a un vacío y la búsqueda de una nueva ley, la que demandan los nuevos movimientos sociales. Podemos pensarlo desde el encuentro con nuestros pacientes jóvenes, su demanda y su forma de posicionarse en el vínculo terapéutico. La dificultad de encontrarse con el otro, de establecer los límites del goce, el destino del sujeto como ser social.

Recalcati nos dirá que la neurosis actual surge de esta carencia, la falta de la herencia. En un mundo en que todos somos jóvenes, no hay herencia ni legado.

Vale la pena subrayar en este punto el trabajo del autor con este concepto de herencia. Se preguntará: ¿qué supone heredar? Heredar la experiencia de ser con otros, de conocer nuestra propia filiación para superarla de algún modo, integrarla a lo que somos. Heredar la posibilidad de sublimar nuestras pulsiones, la ley de la palabra, los límites y la deuda simbólica con la generación anterior. Sin herencia, somos esclavos del goce mortífero, de la caída del deseo.

A través de ejemplos tomados del cine y de la literatura, Recalcati da muestra del sentimiento de declive real o simbólico del lugar de la autoridad dogmática, desde la iglesia (tradición judeo-cristiana) y la política (carente de ideales y corrupta), hasta la intimidad del hogar. El lugar de la autoridad, del límite del goce, parece ya no pertenecer a nadie.

Para ejemplarizar este goce sin límites, mortífero, el autor analiza la película de Pier Paolo Pasolini 120 días en Sodoma, una obra conocida por ser censurada en muchos países e incluso un desafío para el televidente por la cualidad sádica y escatológica de su contenido. Recalcati señala este lugar del goce del uno sin considerar la existencia de un otro, del deseo del otro que representa el límite del nuestro. 
Heredar, para Recalcati, supondrá un movimiento, una manera de volver atrás para avanzar, de obtener el legado, la enseñanza de considerar a otro, otro diferente que no es un objeto para satisfacer nuestras necesidades, sino un límite a nuestro goce mortífero, un límite necesario que alimenta nuestro deseo.

En el espacio que me permite esta reseña no pretendo trasmitir los detalles de este ensayo. Sin embrago, creo que se resaltan algunas aristas interesantes de su tesis principal. Como mencionaba anteriormente, esta obra es valiosa como insumo, ya que nos permite pensar nuestro hacer cotidiano y los desafíos que nos presenta la actualidad. Por otra parte, debemos pensarla a la luz de las nuevas complejidades y diversidades familiares que nos interpelan, con el fin de enriquecer estos aportes.

No se profundiza en torno a qué supone el lugar del padre alejado del destino del propio sexo; el lugar de la función paterna, que puede ser ejercida por distintos actores en la vida del niño, el adolescente, el joven. Si bien Recalcati subraya que el declive del padre autoritario es un movimiento necesario, que supone un cambio esperado, no profundiza acerca de las nuevas familias y cómo puede inscribirse en ellas la ley de la palabra, el lugar del padre como el lugar de aquel que otorga la herencia. Por otra parte, problematizar en lo que refiere al límite como esencial para un desarrollo psíquico sano también puede ser necesario. En estos tiempos de apertura a nuevos modelos, vale la pena investigar si el acompañamiento y la contención pueden ser alternativas en una nueva función paterna, acompañar a las nuevas generaciones en su encuentro con la otredad. Estos pueden ser puntos interesantes para desarrollar.

De todas formas, a pesar de estos posibles atravesamientos que están ausentes en la obra, así como también de los sesgos propios del autor referidos a su formación lacaniana y a su inscripción en determinadas 
instituciones psicoanalíticas, encontrar ensayos de un psicoanalista que produce teoría desde su experiencia y nos invita a pensar el malestar actual siempre es un recurso valioso. De este modo, internarnos en su lectura y pensar qué disparadores despierta es una experiencia necesaria y transformadora. 
